\title{
RANCANGAN KEBIJAKAN BUDAYA ORGANISASI UNTUK PENINGKATAN KAPABILITAS BANK SENTRAL
}

\author{
Widyo Gunadi ${ }^{1}$,Eriyatno ${ }^{2}$, M. Parulian Hutagaol ${ }^{3}$, dan Muliaman D Hadad ${ }^{1}$ \\ ${ }^{1}$ Bank Indonesia (BI), Jakarta \\ ${ }^{2}$ Departemen Teknologi Industri Pertanian, Fakultas Teknologi Pertanian, \\ Institut Pertanian Bogor \\ ${ }^{3}$ Departemen Ilmu Ekonomi, Fakultas Ekonomi dan Manajemen, \\ Institut Pertanian Bogor \\ Artikel diterima April 2012 \\ Artikel disetujui untuk dipublikasikan Juli 2012
}

\begin{abstract}
The aim of this study is to develop policies of organization culture $(O C)$. The policies analysis cover management process and its changing in Bank Indonesia, including direction and substance of OC, developing ideal models, methods, dynamic change and its management. Awareness about the importance of $O C$ in improving the performance of the organization had been recognized by management of Bank Indonesia in the surface, but when examined the dynamics of the changes, the implementation seem fluctuated. Using a system approach, this research employ three main tools: Analytical Network Process (ANP), Strategic Assumption Surfacing and Testing (SAST), and Interpretative Structural Modeling (ISM). The knowledge base data are compiled using combination of several methods: survey, focus group discussion (FGD), statistics of secondary data, and structured in depth interviews. This research has found the new values which should be adopted for BI are integrity professional, visionary, competence, and transparent. Besides, it also delevelop models to implement a new organization culture management. In terms of organization culture change program, this research uncovers several important phenomena such as: the central role of the board of governor, the function of performance management and assessment, and the role of director in every unit.
\end{abstract}

Keywords: Organization Culture, Values,Sub-culture Type, Analytical Network Process, Strategic Assumption Surfacing and Testing, Interpretative Structural Modeling

\begin{abstract}
ABSTRAK
Tujuan penelitian ini adalah untuk mengembangkan kebijakan budaya organisasi (BO). Analisis Kebijakan meliputi proses manajemen dan perubahannya di Bank Indonesia, termasuk arah dan substansi BO, dengan mengembangkan model-model yang ideal, metode-metode, perubahan dinamis dan manajemennya. Pada tingkat permukaan, kesadaran akan pentingnya BO dalam meningkatkan kinerja organisasi telah diakui oleh manajemen Bank Indonesia, walaupun ketika meneliti dinamika perubahan, pelaksanaannya tampak berfluktuasi. Dengan menggunakan satu pendekatan sistem, penelitian ini memakai tiga alat utama: Analytical Network Process (ANP), Strategic Assumption Surfacing and Testing (SAST), and Interpretative Structural Modeling (ISM). Data dikumpulkan dengan menggunakan perpaduan dari beberapa metode: survey, focus group discussion (FGD), statistik data sekunder, dan wawancara yang terstruktur dan mendalam. Penelitian ini telah menemukan nilai-nilai baru yang harus diadopsi oleh Bank Indonesia, seperti integritas profesional, kevisioneran, kompetensi, dan transparansi. Selain itu, penelitian ini juga mengembangkan model-model yang menerapkan satu manajemen budaya organisasi yang baru. Dalam hal program perubahan budaya organisasi, penelitian ini mengungkapkan beberapa fenomena penting seperti: peran sentral dewan gubernur, fungsi manajemen kinerja dan penilaian, serta peran direktur di setiap unit.
\end{abstract}

Kata kunci: Budaya Organisasi, Nilai, Tipe Sub-budaya, Analytical Network Process (ANP), Strategic Assumption Surfacing and Testing (SAST), and Interpretative Structural Modeling (ISM). 


\section{Pendahuluan}

\subsection{Latar Belakang}

Bank Indonesia, sebagai bank sentral dengan tugas moneter dan perbankan serta mengelola aset lebih dari 1.180 trilyun rupiah, sangat penting untuk mengelola organisasi agar berkinerja tinggi dan berkesinambungan. Elemen mendasar dalam pengelolaan organisasi adalah budaya organisasi (BO). BO dikelola untuk menghasilkan kapabilitas dan perilaku yang dibutuhkan organisasi. Dikelola dalam arti diarahkan untuk mencapai bentuk idealnya, yang selaras dengan misi, visi dan strategi organisasi. Penelitian sebelumnya menunjukkan bahwa budaya organisasi yang cocok dan kuat, meningkatkan kinerja organisasi.

Namun demikian, fakta menunjukkan bahwa pengelolaan belum efektif, yang disebabkan berbagai kendala seperti : Pertama, masih banyak manajemen puncak yang berpendapat bahwa BO adalah suatu kondisi yang tidak dapat diubah. Kedua, kekurangan informasi dan contoh konkret mengenai: bagaimana menentukan kultur ideal yang cocok untuk organisasi, bagaimana melakukan perubahan perilaku kolektif, efektifitas program perubahan, contoh sukses pengelolaan BO sebagai anutan untuk adopsi perubahan. Ketiga, masalah pengukuran keberhasilan. Pengelolaan BO membutuhkan alat ukur yang lebih terlihat dan mudah dipahami agar pihak manajemen mau investasi di bidang ini, baik waktu, biaya dan perhatian. Untuk kasus BI, sebenarnya sejak tahun 2002 telah mencoba melakukan program perubahan kultur, namun belum menunjukkan hasil seperti yang diharapkan.

\subsection{Identifikasi dan Formulasi Permasalahan}

Organisasi dapat memiliki masalah jika : kinerja organisasi turun/rendah, kelangkaan sumberdaya baik kuantitas maupun kualitas, manajemen organisasi yang tidak efisien. Ditinjau dari perspektif waktu permasalahan manajemen dapat dikelompokan dari jangka panjang sampai jangka pendek yang berimplikasi dalam permasalahan direktif, strategis, taktis, dan operasional.

Dari luasnya permasalahan organisasi yang dihadapi oleh BI, penelitian fokus pada permasalahan kultur. Hal ini didasarkan pada : Pertama, alur pikir deduktif dengan kerangka kerja Kaplan-Norton (2004) yang pada akhirnya untuk menjamin kinerja tinggi dan berkesinambungan, harus dipersiapkan organisasinya (organization readiness), Kedua, dari penelitian PPSK sebelumnya tentang kepuasan pegawai yang masih rendah. Ketiga, dari analisa situasional pelaksanaan program perubahan kultur yang belum sesuai harapan. Penelitian ini mengidentifikasi 3 permasalahan utama:

Permasalahan Values sebagai Inti Kultur

Nilai strategis (values) adalah nilainilai yang dibutuhkan untuk menjamin strategi oganisasi tercapai. Dari analisa situasional dapat diformulasikan permasalahan values di Bank Indonesia:

a. Belum adanya pengaturan/ penetapan/ kebijakan nilai-nilai (values) secara komprehensif yang diterima oleh seluruh pegawai dan pimpinan puncak.

b. Implementasi kultur yang menurun, khususnya penilaian stakeholder eksternal.

c. Terbatasnya sumberdaya untuk perubahan kultur.

\section{Integrasi Kultur dan SubKultur}

Subkultur dimaksudkan sebagai kultur organisasi pada tingkat satuan kerja. Dalam pelaksanaan perubahan, baik desain maupun implementasi, masih adanya kebingungan memadukan kultur dan subkultur ini. Dari analisa situasional yang dilakukan, permasalahan tersebut meliputi: 
1. Belum ada pengaturan/ penetapan/ kebijakan subkultur secara komprehensif yang diterima oleh seluruh pegawai dan pimpinan puncak.

2. Budaya Bank Indonesia masih lemah, yang ditunjukkan dengan beberapa indikator: Adanya gap antara kultur ideal dan kultur saat ini, Implementasi values yang semakin menurun, terjadinya konflik nilai, terjadinya konflik elemen subkultur (discrepancy).

\section{Permasalahan Program Perubahan Kultur Organisasi}

Permasalahan implementasi values dan kesesuaian subkultur erat kaitannya dengan upaya mengubah kultur (culture change program). Dari in depth interview dan FGD ada tiga permasalahan yang cukup menonjol adalah : legitimasi dan konsensus desain perubahan, disiplin implementasi yang rendah, kurangnya keterlibatan aktif dari pimpinan puncak.

\subsection{Tujuan Penelitian}

Tujuan penelitian adalah : 1) Merancang model konseptual kultur ideal di BI sesuai dengan kebutuhan dan tugas BI, 2) Merancang Model Pengelolaan Kultur di BI yang efektif dan berlanjut. Dengan dua rancangan ini diharapkan BI mampu mendesain kebijakan bidang kultur organisasi di BI yang komprehensif yang efektif untuk meningkatkan kapabilitas organisasi.

\section{Tinjauan Pustaka}

\subsection{Konsep Budaya Organisasi}

Budaya Organisasi (BO) adalah konsep makro yang mewakili perilaku organisasi atau perilaku kolektif anggota organisasi. Schein (1992), mendefinisikan BO sebagai: pola asumsi dasar yang dipraktekkan organisasi untuk adaptasi dengan eksternal dan internal integrasi. Asumsi dasar terdiri dari nilai-nilai (values) yang diyakini dan dipraktekkan dalam proses-proses kerja. Sementara itu, Cameron \& Quinn membagi tipe BO dalam empat kuadran: Adhocracy, Market, Hierarchy dan Clan. Framework ini dapat digunakan untuk mengidentifikasi BO organisasi atau bisnis kedalam tipe-tipe kultur. Tipe kultur yang berkembang saat ini, tipe kultur yang ideal atau seharusnya dikembangkan. Jurang perbedaan (gap) antara tipe yang ideal dan tipe saat ini menjadi arah dari tranformasi kultur yang harus dilakukan. Quinn-Cameron membuat alat pengukuran kultur yang terkenal dengan metode OCAI (Organization Culture Assessment Instrument). Secara lebih konkret, Toyohiro Kono (1998) berpendapat ada tiga lapisan kultur : nilai bersama (shared values), pola pengambilan keputusan dan perilaku yang tampak

\subsection{Kapabilitas Organisasi}

Dalam framework penelitian, kultur organisasi diformulasikan untuk meningkatkan kapabilitas organisasi. Kapabilitas organisasi adalah kemampuan organisasi dalam menjalankan misi, visi dan strateginya, jadi bukan kemampuan dalam arti umum. Ulrich (1999) berpendapat bahwa kapabilitas ini terdiri dari 4 elemen : 1) share-mindset (baik dari sisi cara maupun tujuan, 2)Management Practise, 3) leadership, 4) kapasitas untuk berubah.

\section{Metodologi Penelitian}

Oleh karena kebijakan kultur melibatkan berbagai variabel dalam suatu sistem kompleks, dinamis dan bersifat probabilistik, penelitian ini dilakukan dengan menggunakan pendekatan sistem dengan kerangka pemikiran sebagai berikut: 


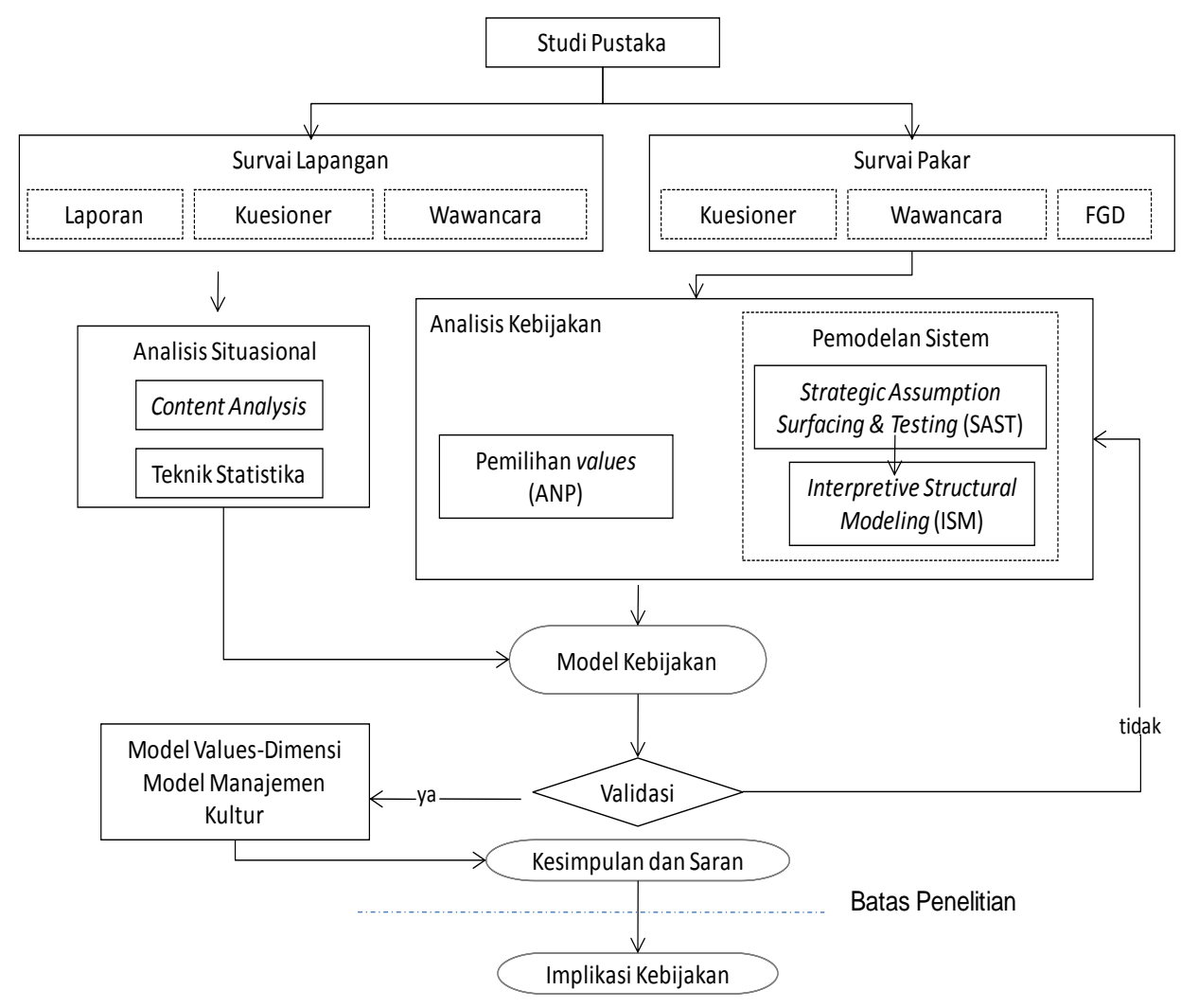

Gambar 1. Tahapan Penelitian

\subsection{Tempat, Waktu dan Responden Ahli}

Analisa Situasional dilakukan pada kurun waktu Januari 2009 sampai dengan Desember 2010. Namun, beberapa data sekunder dianalisa sejak tahun 2002 sampai dengan 2009 baik mengenai implementasi values maupun pencapaian subkultur tiap satuan kerja. Pada analisis kebijakan, penelitian menggunakan tiga alat penelitian utama : ANP, SAST dan ISM yang pada dasarnya kelompok Soft System Methodology. Pada metode ini data dan informasi didapat dari pengetahuan dan pengalaman (knowledge based) yang ada pada responden ahli atau pakar. Dari batasan organisasi pakar dibedakan dua kelompok: internal BI dan eksternal dari berbagai kelompok kepentingan seperti : DPR, BPK, BSBI, media masa, akademisi, pemerintah dan tokoh masyarakat. Dari sisi keahlian dapat dibedakan : ahli kultur, ahli BI, ahli perubahan dan ahli metodologi. Total responden ahli adalah 55 orang.

\subsection{ANP (Analitical Network Process) \\ ANP digunakan untuk} merumuskan values ideal dengan format seperti pada Gambar 2. Pada intinya ANP adalah alat untuk memilih variabel dalam suatu cluster namun terhubung (network) baik dengan cluster lainnya maupun dalam cluster sendiri. Dengan metode ANP ini, pemilihan values tidak ditentukan secara turun-menurun atau arbitrase, namun dipilih dalam konteks dengan kluster lainnya yang relevan, seperti misi-visitugas, kebutuhan eksternal, kebutuhan internal, leadership yang dirinci dalam masing-masing sub elemen. 
KERANGKA ANP PADA SUPER DECISIONS

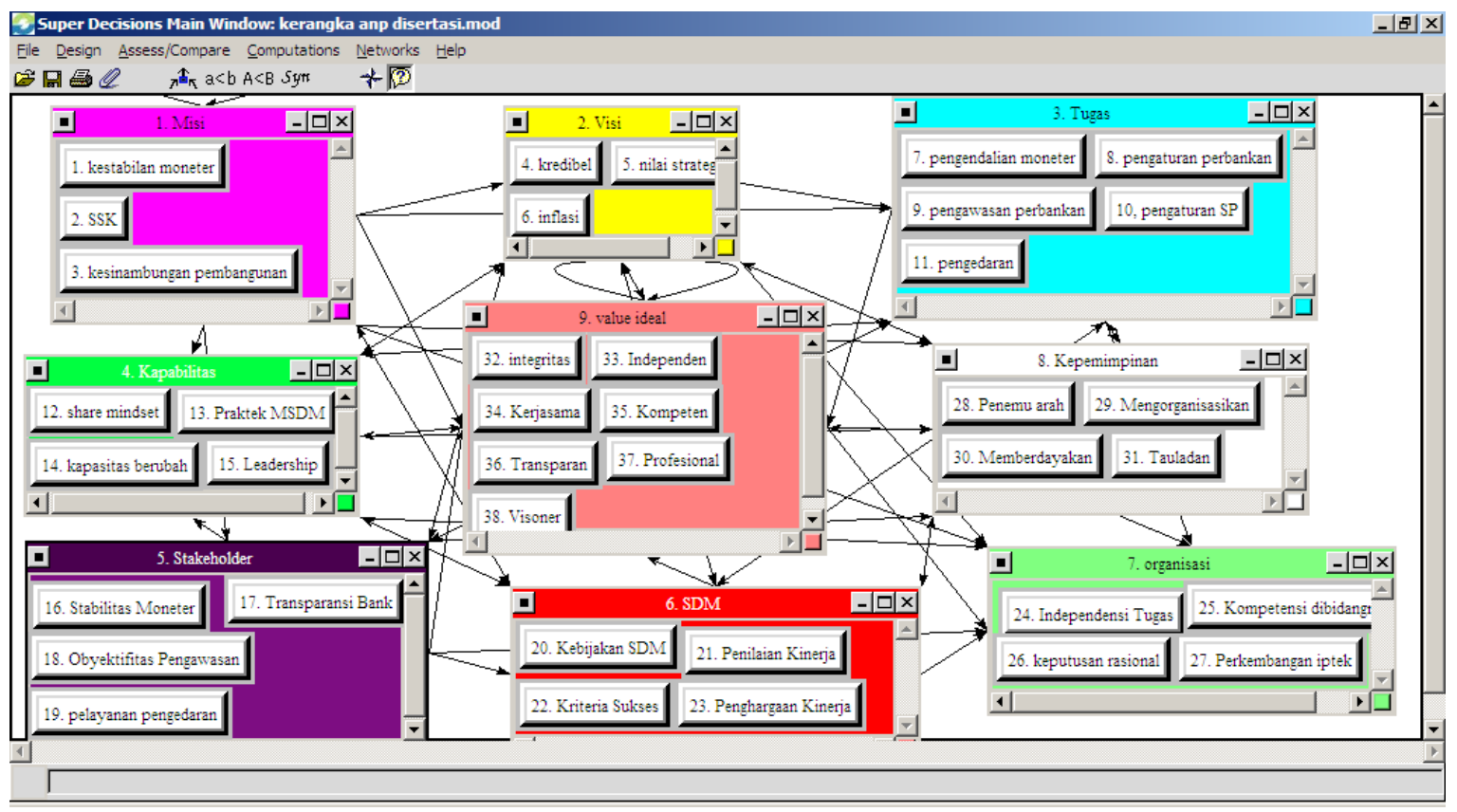

Gambar 2. Kerangka ANP Pemilihan Values

\subsection{SAST (Strategic Asumption Surfacing and Testing)}

Untuk membangun asumsi-asumsi strategis dalam penyusunan progam pengelolaan kultur digunakan metode SAST. Dalam pembuatan suatu kebijakan, tidak semua variabel dapat dikontrol atau menjadi input kebijakan, namun tetap diperhatikan dan menentukan desain kebijakannya. Variabel yang tidak dapat dimasukkan atau diselesaikan digunakan sebagai asumsi, baik berupa kendala, faktor penghambat, kondisi yang tidak mungkin dapat dirubah serta perihal kesepakatan para stakeholder. Pencarian asumsi-asumsi dasar dapat diperoleh dari FGD dengan responden pakar yang berpengalaman baik dibidang substansi perubahan (culture-leadership) maupun manajemen perubahan (change management).

\subsection{ISM (Interpretative Sructural Modeling)}

Untuk merumuskan program perubahan budaya organisasi yang sesuai digunakan alat ISM yang berguna untuk membuat struktur sub elemen pada tiap elemen program. ISM pada intinya membuat struktur sub elemen dari 4 macam hubungan antar sub elemen, sebagai contoh : mendukung, didukung, saling mendukung atau sama sekali tidak terkait. Empat macam hubungan ini dilambangkan dengan VAXO.

\section{Hasil dan Pembahasan}

\subsection{Formulasi Values Ideal}

Dari hasil penelitian dengan (ANP) diatas didapatkan bahwa Bank Indonesia perlu values baru yang lebih sesuai dengan kebutuhan. Pada Tabel 3 diatas terlihat urutan prioritas yang terpilih. Berdasarkan pendapat pakar gabungan, prioritas pertama pada kluster ini adalah integritas dengan proporsi nilai limit 0.03 , selanjutnya prioritas kedua dan ketiga value ideal yang dicari adalah professional dan visioner.

Dengan demikian urutan lima besar values adalah: integritas, profesional, visioner, kompeten dan transparan. Ini 
menarik karena akan mengubah values yang sekarang dianut yakni KITA-K (Kompetensi, Integritas, Transparansi, Akuntabilitas dan Kebersamaan). Ini berbeda dengan values saat ini (existing) yakni KITAK (Kompetensi-IntegritasTransparansi-Akuntabilitas-Kebersamaan).
Dari berbagai IDI tampak bahwa KITA-K bukanlah hasil suatu urutan prioritas yang tersistem. Untuk melihat tingkat persetujuan antar ahli (rater agreement), digunakan Kendall's coefisien concordance, yang secara gabungan adalah 0.62 berarti cukup memadai

Tabel 1. Hasil Peringkat Komponen dalam Kluster Value Ideal yang Dicari

$\mathrm{P}$ : Peringkat ; Nilai : nilai komposit eigen factor

\begin{tabular}{|l|c|c|}
\hline \multirow{2}{*}{\multicolumn{1}{|c|}{ Cluster Values Ideal yang Dicari }} & \multicolumn{2}{c|}{$\begin{array}{c}\text { Seluruh } \\
\text { Pakar }\end{array}$} \\
\cline { 2 - 3 } & Nilai & P \\
\hline Integritas & 0.03271 & 1 \\
\hline Profesional & 0.02730 & 2 \\
\hline Visioner & 0.02580 & 3 \\
\hline Kompeten & 0.02530 & 4 \\
\hline Transparan & 0.01410 & 5 \\
\hline Independen & 0.01400 & 6 \\
\hline Kerjasama & 0.01120 & 7 \\
\hline
\end{tabular}

ANP pada penelitian ini melibatkan responden ahli berjumlah 41 orang, yaitu gabungan pakar internal berjumlah 15 orang, dan pakar dari eksternal berjumlah 26 orang. Menarik pula dibahas disini adalah 3 urutan prioritas dari 37 variabel yang diteliti yakni : elemen tauladan (0,07), kredibilitas (0.07), kompetensi di bidangnya (0,06). Elemen tauladan merupakan bagian terpenting dari kluster kepemimpinan, hal ini berarti bahwa salah satu kriteria yang diharapkan adalah sikap ketauladanan dari pimpinan. Kredibilitas adalah bagian dari kluster visi dan hasil dari gabungan kinerja dan values yang dianut. Kompetensi di bidangnya merupakan salah satu elemen dari kebutuhan internal MSDM, ini menggambarkan pentingnya elemen ini dalam keseluruhan sistem.

\subsection{Asumsi Model Kebijakan Kultur}

Hasil identifikasi faktor kebijakan budaya organisasi yang dibahas dalam diskusi pakar, dikelompokan dalam tiga aspek, yaitu aspek eksternal organisasi, internal organisasi (sistem MSDM), dan internal organisasi (sistem pengelolaan organisasi). Dengan metode strategic assumption surfacing and testing (SAST), yang dilakukan dalam diskusi pakar ditentukan nilai kepentingan dan kepastian dengan mengacu pada pertanyaan yang meliputi: (1) seberapa penting pengaruh asumsi tersebut terhadap keberhasilan atau kegagalan, dan (2) seberapa besar keyakinan bahwa asumsi yang dimunculkan dapat dibenarkan dan dipastikan keberhasilannya.

Hasil penilaian setiap responden ahli digabungkan dengan menghitung ratarata geometris dari setiap pernyataan sehingga diperoleh tingkat kepentingan dan kepastian asumsi dasar kemudian disajikan dengan tabel. Apabila diplot dalam dalam diagram cartecian terlihat pada gambar 3 dibawah. Pada dasarnya asumsi-asumsi yang terletak pada kuadran I, III dan IV dapat diabaikan dalam penyusunan model.

Pada kuadran II dengan kepastian dan kepentingan yang tinggi yaitu: (1) Sistem penilaian kinerja (asumsi H), (2) Sistem pemenuhan (rekruitmen, promosi, 
mutasi) dan sistem penilaian kompetensi/potensi pegawai (sintesa G,I), (3) Undang-undang bank sentral, sistem reward dan penalty serta sistem manajemen kerja organisasi (sintesa $\mathbf{C , K , P ) , ~ ( 4 ) ~ S i s t e m ~ p e n g e m b a n g a n ~ d a n ~}$ sistem audit (sintesa J,Q), (5) Business process (proses kerja) dan Job design delegasi wewenang (sintesa N,O). Selanjutnya asumsi pada kuadran II ini digunakan sebagai dasar dan pertimbangan penting dalam penyusunan model kebijakan pengelolaan budaya organisasi.

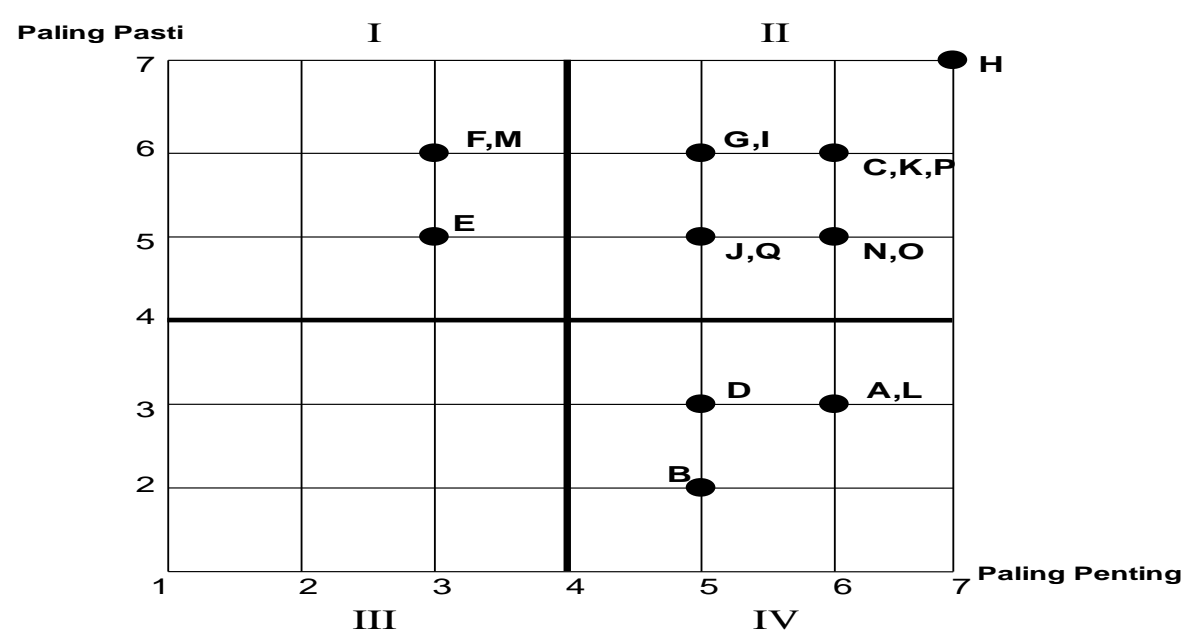

Gambar 3. Peta Asumsi Kebijakan Pengelolaan Budaya Organisasi

\subsection{Struktur Program Perubahan}

Pada penelitian ini menggunakan seluruh elemen sebagaimana disarankan oleh Saxena (1992) yang terdiri 9 elemen yang disajikan dalam tabel 2. Pada makalah singkat ini dibahas satu elemen sebagai contoh pembentukan struktur. Untuk elemen yang lain disajikan pada tabel 2 tersebut, yang memuat informasi penting yakni sub elemen kunci (yang memiliki driver power terbesar dalam elemen, serta sub elemen yang berada pada kuadran III (lingkages) yang sangat penting dan harus diperhatikan dalam penyusunan program.

\subsection{Elemen Aktivitas Perubahan dalam Pengelolaan Budaya Organisasi}

Elemen aktivitas perubahan terdiri atas delapan sub elemen, seperti terlihat dalam gambar 4 dan gambar 5. Penilaian pakar terhadap hubungan kontekstual antar sub elemen aktivitas perubahan dilakukan dengan pendekatan V, A, X dan O. Hasil penilaian hubungan setiap sub elemen akan menghasilkan reachability matriks, yang selanjutnya digunakan dalam pembuatan deskripsi baik dalam gambar klasifikasi per kuadran, maupun dalam struktur sub elemen.

Pada Gambar 4 di sektor II (driver power rendah dan ketergantungan tinggi), sub elemen yang termasuk didalamnya adalah sinkronisasi dengan program pengembangan organisasi dan SDM (3), program dampak cepat 'quick win' (7) dan melaksanakan program komunikasi (8). Ketiga sub elemen ini memiliki daya pendorong (driver power) rendah dan bersifat dependent sehingga keberadaan sub elemen tersebut sangat bergantung pada sub elemen lainnya dalam pengelolaan budaya organisasi. 


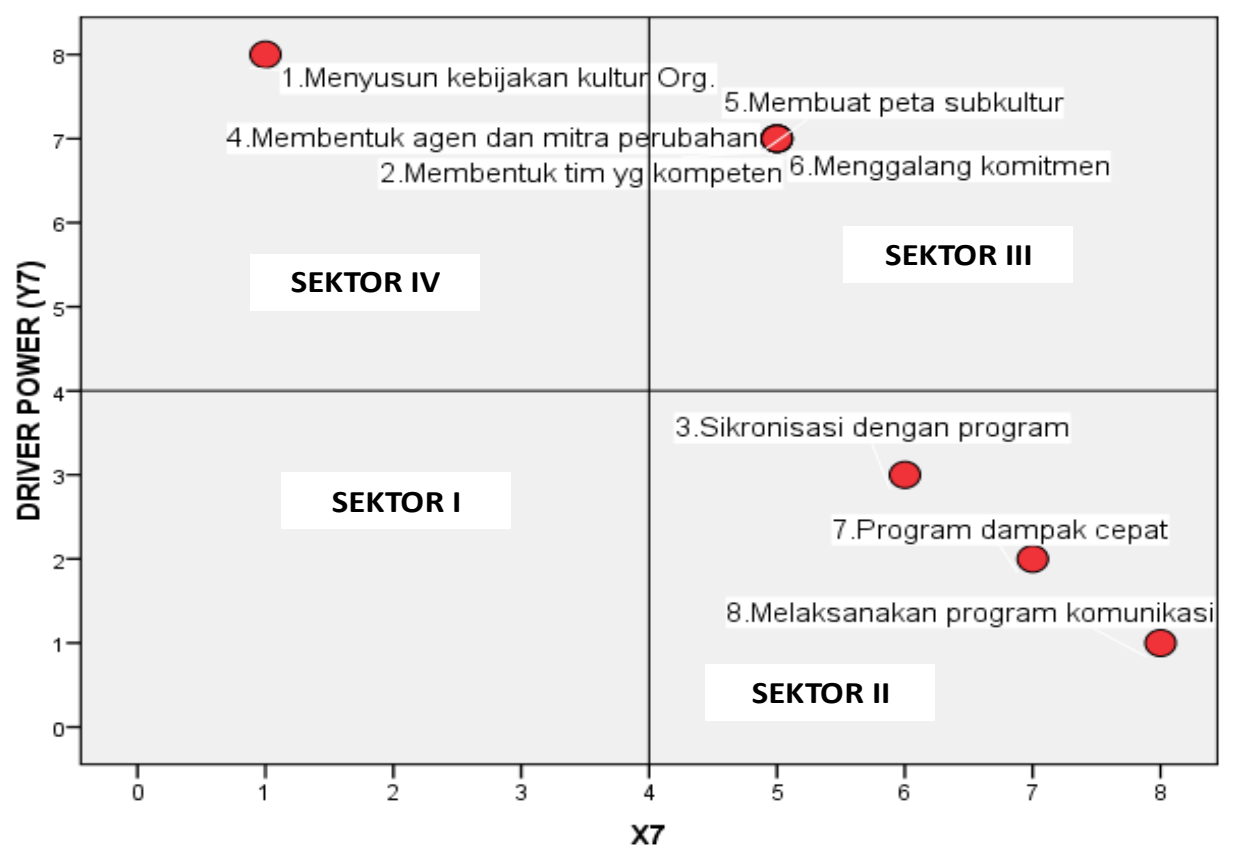

Gambar 4. Klasifikasi Elemen Aktivitas Perubahan Berdasarkan Driver Power Dependence

Pada sektor III (peubah linkage) sub elemen terdiri dari membentuk tim yang kompeten (2), membentuk agen dan mitra perubahan (4), membuat peta subkultur (5), dan menggalang komitmen dukungan pimpinan (6). Sektor III adalah sektor yang penting karena terkait langsung dengan program.

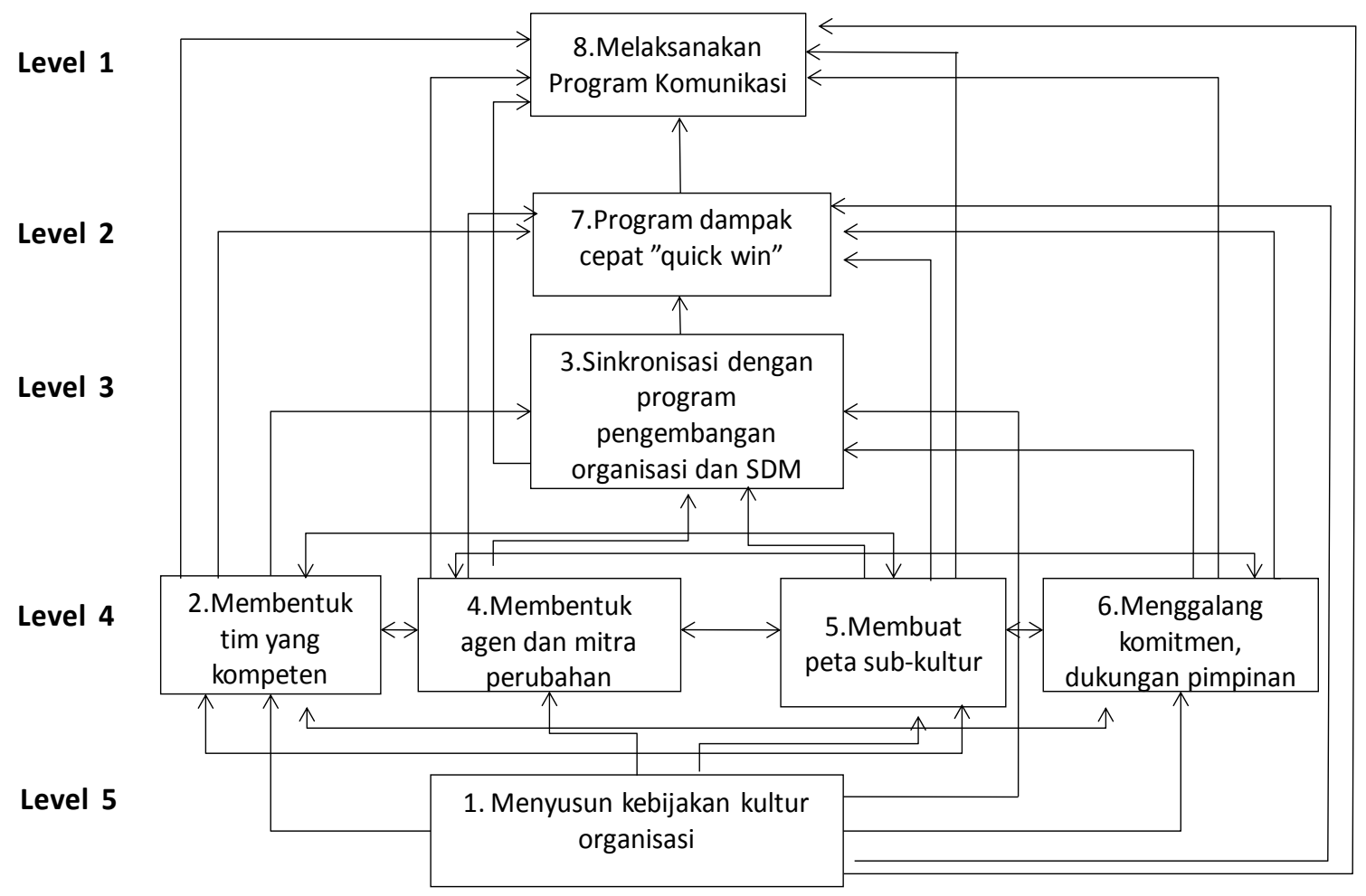

Gambar 5. Level Hirarki dan Hubungan Elemen Aktivitas Perubahan 
Pada sektor IV (independen), sub elemen yang termasuk adalah menyusun kebijakan kultur organisasi (1). Sub elemen ini memiliki daya pendorong terbesar (sub elemen kunci) sangat kuat atau dapat bertindak sebagai motor penggerak terhadap sub elemen yang lain. Selain itu, sub elemen ini juga memiliki tingkat ketergantungan yang paling rendah atau independent. Sub elemen kunci dapat menjadi semacam starter dalam membuat program.

Dengan cara analisa yang sama, riset ini telah meneliti sembilan elemen secara lengkap dan menghasilkan struktur setiap elemennya. Pada Tabel 2 dibawah disajikan seluruh temuan dan harus menjadi pertimbangan dalam membuat program perubahan kultur.

Tabel 2. Ringkasan Elemen Program Peningkatan Kultur

\begin{tabular}{llll}
\hline No & Elemen Program & Sub Elemen Kunci & $\begin{array}{l}\text { Sub Elemen Sektor III } \\
\text { (Linkages) }\end{array}$ \\
\hline 1. & $\begin{array}{l}\text { Stakeholder yang } \\
\text { Terpengaruh }\end{array}$ & Dewan Gubenur (1) & Manajer Menengah (3), Unit \\
Kerja (5)
\end{tabular}




\subsection{Model Konseptual}

Berdasarkan Analisis Situasional dan Analisa Kebijakan khususnya dengan SAST dan ISM dapat disusun model konseptual yang terdiri dari : model manajemen kultur, model kelembagaan pengelolaan kultur, model kelembagaan pengelolaan subkultur. Dalam paper singkat ini disajikan model manajemen kultur sebagai contoh, sebagaimana gambar berikut.

Tujuan dari model manajemen kultur adalah mengintegrasikan seluruh elemen yang penting dalam hubungan keterkaitan. Model ini kemudian dilengkapi dengan model kelembagaan yang bertujuan mengintegrasikan peran semua aktor dalam pengelolaan kultur. Dari sisi elemen struktur, sebagaimana temuan ISM, Dewan Gubernur, kelompok perwakilan direktur sebagai semacam "dewan pertimbangan kultur" sangat dibutuhkan eksistensinya. Demikian juga adanya elemen stakeholder eksternal yang ikut menentukan dinamika organisasi. Dengan pendekatan sistem semacam ini akan diperoleh suatu proses organisasi yang hidup dalam pengelolaan kultur organisasi.

Dari sisi hubungan antar elemen dapat dilihat hubungan koordinasi/order dan hubungan umpan balik yang menjadi unsur penting dalam sistem yang utuh.

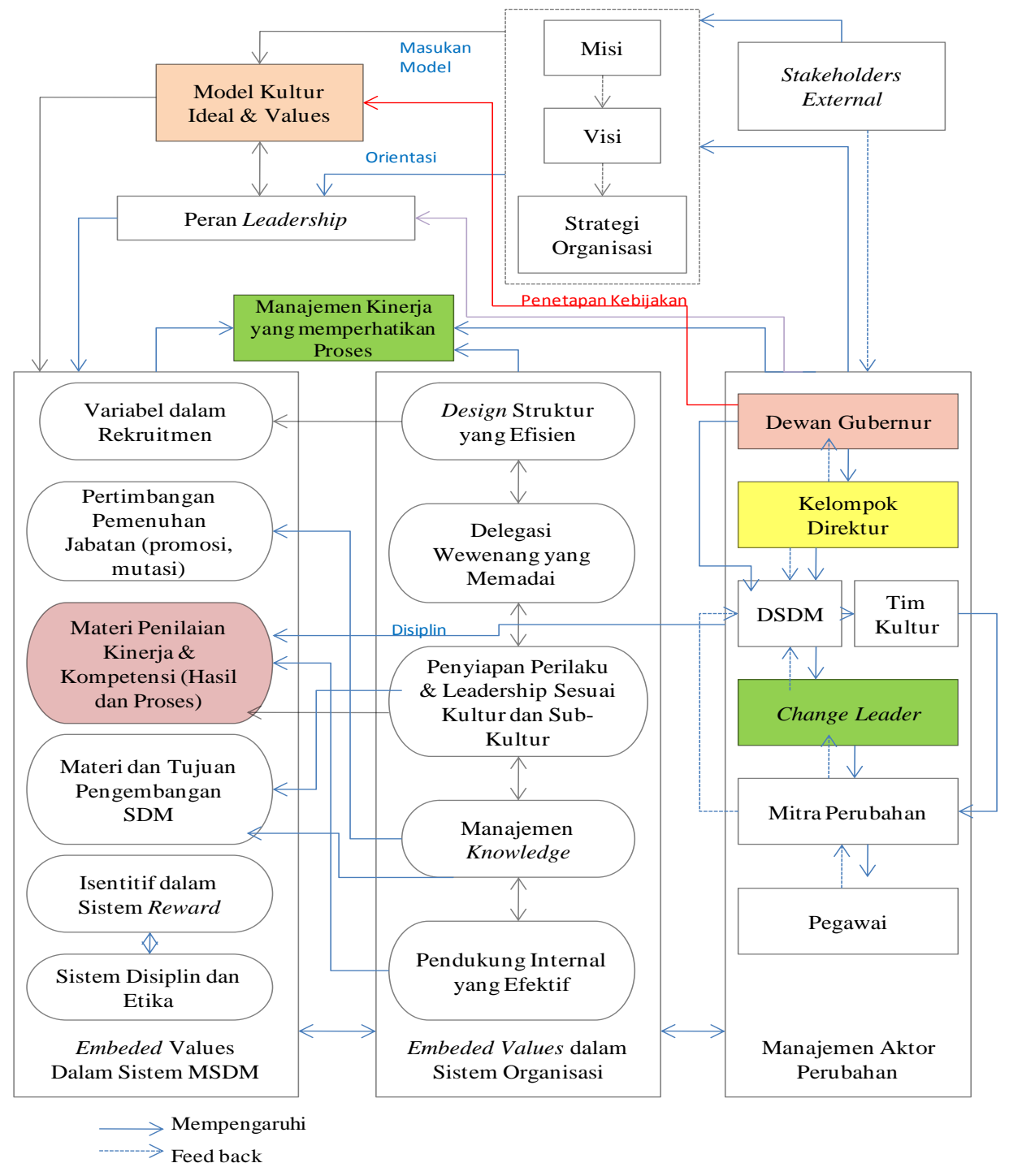

Gambar 6. Model Manajemen Kultur Bank Indonesia (BI) 


\section{Kesimpulan dan Saran}

Hasil riset ini menunjukkan bahwa BI perlu memiliki model ideal kultur yang baru yang bertumpu pada values Integritas, Profesionalisme dan Visioner sebagai values inti. Ditambah dengan values kompeten dan transparan menjadi nilai strategis yang baru menggantikan nilai strategis yang lama. Selanjutnya nilai strategis ini menjadi pilar kultur BI dan diintegrasikan dengan subkultur. Integrasi ini, dinamakan Model Values-Dimensi perlu dibuat model manajemen.

Untuk mencapai model ideal kultur diperlukan program perubahan kultur. Riset ini juga telah mengidentifikasi faktor-faktor kunci yang harus dipertimbangkan untuk seluruh elemen programnya. Dengan dasar ini dibangun model perubahan kultur yang terdiri dari 3 model : model manajemen kultur BI, model kelembagaan pengelolaan kultur, model kelembagaan pengelolaan subkultur.

Pada model manajemen kultur, seluruh elemen utama kebijakan diintegrasikan untuk menghasilkan kultur ideal. Beberapa elemen yang ditemukan sangat esensial dari riset ini adalah: peran penilaian kinerja pegawai, peran dewan gubernur sebagai inisiator, peran leadership di level unit kerja, dan perlunya kebijakan yang jelas dan tegas mengenai kultur.

Model kelembagaan mengintegrasikan peran seluruh pelaku utama dalam pengelolaan kultur. Beberapa elemen yang penting dari riset ini adalah : peran tauladan pimpinan, perlunya pimpinan unit sebagai change leader, perlunya lembaga perwakilan direktur sebagai badan pertimbangan, perlunya mengelola pendapat stakeholder eksternal secara tersistem, peran direktur SDM yang sentral dalam integrasi dengan sistem MSDM. Di level subkultur elemen tersebut perlu ditambah dengan peran mitra perubahan kultur dan sistem umpan balik dari stakeholder utama.

$$
\text { Implementasi dari model }
$$
konseptual tersebut tentu memerlukan langkah dan keputusan yang lebih operasional diantaranya adalah: diterbitkannya PDG Kultur BI sebagai keputusan direktif dan strategis BI, pencanangan program kultur oleh GBI, ada satu DpG yang memimpin, dibentuknya tim kultur yag kompeten, dan Komite Kultur dari Kelompok Direktur.

\section{Daftar Pustaka}

Cameron , K.S. and R. E Quinn. 1999. Diagnosing \& Changing Organizational Culture. Based on the Competing Values Framework .Addison-Wesley.

Checkland, P. 1995. Model Validation in Soft Systems Practice. System Research Vol 12 No 1 pp 47-54. Department of Management Scienc, University of Lancaster.

Cooper, D.R and P. S. Schindler. 2003. Business Research Methods. Eight Edition. McGraw Hill/Irwin Series. New York.

Eriyatno dan F. Sofyar. 2007. Riset Kebijakan. Metode Penelitian Untuk Pascasarjana. IPB Press.

Goelzer, P.G. 2002. Effects of national Culture on Organizational Culture. Benedictine University.

Jackson, M. C. 2003. System Thinking Creative Holism for Managers. University of Hull, UK. John Wiley \& Sons Ltd.

Kaplan, R. S \& D.P Norton. (2004) Strategy Maps. Converting Intangible assets into tangible 
outcomes. Harvard Business School Publishing Co.

Kotter, P. 1996. Leading Change. Harvard Business School Press.

Lau, C.M., D.K. Tse and Nan Zhou. Institutional Forces and Organizational Culture in China: Effects on Change Schemas, Firms Commitment and Job Satisfaction.

Mangkuprawira, S. 2003. Manajemen Mutu Sumber Daya Manusia Strategik. Ghalia Indonesia.
Marimin. 2005. Teori dan Aplikasi Sistem Pakar dalam Teknologi Manajerial. IPB Press.

Schein, E.H (1999). Corporate Culture. Jossey Bass, John Wiley \& Sons, Inc.

Ulrich, D. and D. Lake. Organizational Capability. Competing From the Inside Out. (1990). John Wiley \& Sons Co. Canada. 